\title{
An Unusual Case of Gallbladder Carcinoma with Pseudopancreatic Cyst
}

\author{
Nahin Akhtar ${ }^{1}$, Huma Mushtaq², Ahmad Raza ${ }^{3}$ \\ ${ }^{1}$ Fourth Year MBBS Student, Islamabad Medical and Dental College \\ 2 Associate Professor, Department of Pathology, Islamabad Medical and Dental College \\ ${ }^{3}$ Associate Professor, Department of Surgery, Akbar Niazi Teaching Hospital, Islamabad
}

\begin{abstract}
A B S TRACT
Generally, carcinoma of the gallbladder is an extremely unusual neoplasm, however, high incidence rates have been reported in certain parts of the world. The role of certain factors such as genetic susceptibility, lifestyle and infections of gallbladder in causing carcinogenesis is still not clearly understood. Due to its early vague symptoms and lack of serosa in the gallbladder to slow its spread, gallbladder carcinoma typically presents at an advanced stage with a five-year survival rate of less than $5 \%$. Pseudopancreatic cyst is an uncommon but not a rare complication of acute pancreatitis and injury to the pancreas. However, it rarely presents with carcinoma of gallbladder. We present here an unusual case of gallbladder carcinoma with pseudopancreatic cyst in a 58-year old male.
\end{abstract}

Key Words: Gallbladder cancer, Gallstones, Pancreatitis, Pseudo-pancreatic cyst

\begin{tabular}{ll} 
Correspondence: & Article info: \\
Nahin Akhtar & Received: May 15, 2019 \\
Email: nahinakhtar007@gmail.com & Accepted: August 19, 2019 \\
\hline
\end{tabular}

Cite this case Report: Akhtar N, Mushtaq H, Raza A. An Unusual Case of Gallbladder Carcinoma with Pseudopancreatic Cyst. J Islamabad Med Dental Coll-Student Corner. 2019; 8(3):159-162. Doi: 10.35787/jimdc.v8i3.401

Funding Source: Nil Conflict of Interest: Nil

\section{Introduction}

Gallbladder cancer is an extremely rare neoplasm but shows a high incidence rate in certain parts of the world. ${ }^{1}$ Role of infections, lifestyle, genetic susceptibility and other factors in the gallbladder carcinogenesis is still not clearly understood. The incidence rate of gallbladder cancer was 1 to 2.5 per 100,000 in United states. ${ }^{2}$ The incidence rate of gallbladder cancer among females was found to be $13.8 / 100,000$ in Karachi (Pakistan), 21.5/100,000 in Delhi (India) and 12.9/100,000 in Quito (Ecuador). ${ }^{3}$ The incidence ratio of female to male was generally found to be 3:1.3 Gallbladder cancer typically presents at an advanced stage and carries a five-year survival rate of less than $5 \%$. This is due to lack of serosa and early ambiguous symptoms of gall bladder cancer. ${ }^{4}$ The pathogenesis of this cancer follows the progression from metaplasia to dysplasia to carcinoma. ${ }^{5}$ Important risk factor for gallbladder carcinoma is presence of gallstones and it is found in most $(\sim 85 \%)$ of the patients that present with gallbladder carcinoma. ${ }^{6}$ Chronic inflammations is also considered as a major factor for carcinogenesis and malignant transformation. The recurrence of chronic inflammation causes Deoxyribonucleic acid (DNA) damage and further provokes restoration of tissue proliferation. This also causes release of growth factors and cytokines, further predisposing the cells to oncogenic transformation. ${ }^{7}$ According to a new research, diabetes mellitus has also been considered as a risk factor of gall stone formation and this is also associated with the pathogenesis of gallbladder carcinoma. ${ }^{8}$ Previous research has also shown that there is an important role of interaction between exposure to environmental risk factors and innate genetic predisposition in causing carcinoma of gallbladder. There is also an association with family history of gallbladder carcinoma, as the risk of carcinoma gallbladder increases in such cases. ${ }^{9}$ 
Pseudo pancreatic cyst is a rare condition but it can present as a complication of acute pancreatitis and injury to the pancreas ${ }^{10}$ The cyst commonly arises after an episode of acute or chronic pancreatitis. According to literature, it is reported that the prevalence of pancreatic pseudocyst in cases of acute pancreatitis ranges from $6 \%$ to $18.5 \%{ }^{11}$ and in chronic pancreatitis it ranges from $20 \%$ to $40 \% .^{12}$ It also arises in patients with alcoholic chronic pancreatitis (70\% to $78 \%)$. Other causes include idiopathic chronic pancreatitis and biliary pancreatitis. ${ }^{13}$ It is very rare to find pseudo pancreatic cyst as a complication of gallbladder cancer with gallstones. We here present an unusual case of carcinoma of gallbladder with pseudopancreatic cyst.

\section{Case Report}

A 58 year old male, presented in the Out Patient Department of Surgery, Akbar Niazi Teaching Hospital (ANTH) with complaints of pain epigastrium and right hypochondrium for the last one month, associated with nausea and vomiting. There was no history of fever, jaundice, melena or clay coloured stools. Ultrasound was advised and he was diagnosed with symptomatic gallstone disease. Further workup was advised for gallstones but patient compliance was not good. About 6 weeks later, he presented with severe pain epigastrium, radiating towards the back. Abdominal examination revealed a firm mass in the epigastrium, measuring $10 \times 10 \mathrm{~cm}$ in diameter. CTscan revealed pancreatitis with pseudopancreatic cyst and gallstones in the gall bladder with thick irregular, enhancing walls in the fundus of gallbladder, abutting adjacent part of the liver (Figure 1) Two hypodense lesions in segment IV $B$ of the liver with suspicion of malignancy were noted. Pseudocyst was seen in the region of tail and adjacent part of body of pancreas. An open extended cholecystectomy was performed and specimen was sent for histopathological evaluation. Gross examination revealed a mass lesion which comprised of two fragments of gallbladder. The larger fragment with tumor measured $5 \times 4 \times 2 \mathrm{~cm}$ in size. Outer surface of gallbladder was ruptured. On cutting open, the larger fragment showed a fungating tumor diffusely involving the lumen and wall of the gallbladder (Figure 2). Tumor measured $4 \times 4 \mathrm{~cm}$ in diameter. Few calculi were also seen in the lumen. A portion of liver, measuring $2.6 \times 2.3 \mathrm{~cm}$ in size, was seen attached with serosa. Microscopic examination revealed a grade 3 poorly differentiated adenocarcinoma, extending beyond the serosa (Figure 3). Cystic duct margin was uninvolved. Additional findings included cholelithiasis and extensive necrosis of gallbladder wall.

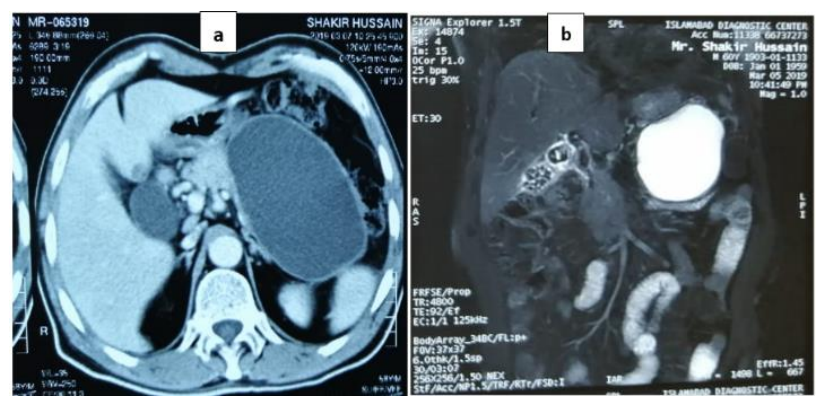

Figure-1(a, b): CT-scan showing pancreatitis with pseudopancreatic cyst and gallstones in Gall bladder with thick irregular, enhancing walls in fundus of gallbladder, abutting adjacent part of liver. Two hypodense lesions in segment IV $B$ of liver with suspicion of malignancy are seen. Pseudocyst is also seen in region of tail and adjacent part of body of pancreas.

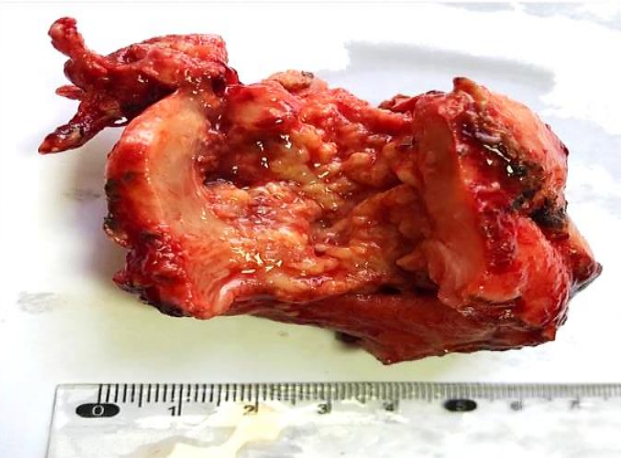

Figure-2: Showing gross specimen of Gall bladder with a fungating tumor diffusely involving the lumen and wall of gallbladder.

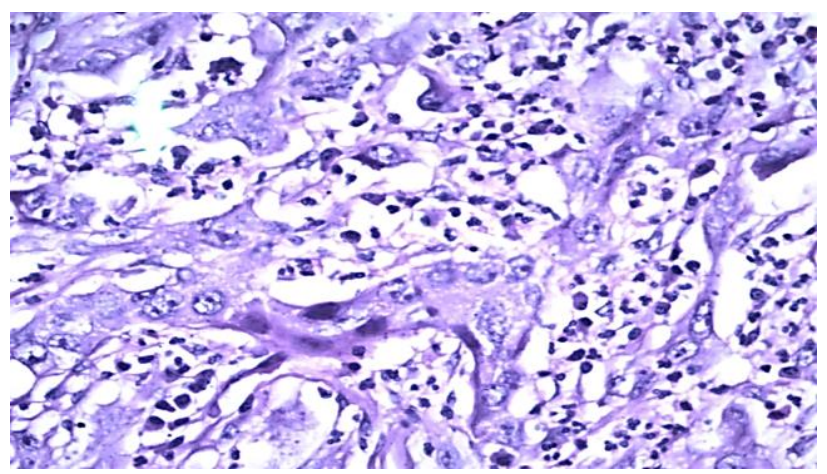

Figure-3: Showing infiltration by Adenocarcinoma with cells having marked pleomorphism and vesicular nuclei (H\&E x 400). 


\section{Discussion}

A gallbladder cancer is an extremely rare malignancy with a high mortality rate. ${ }^{3}$ Chronic inflammation of the gallbladder wall with subsequent cellular proliferation and large gallstones or chronic Salmonella typhi infection are the common risk factors for gallbladder cancer. The high rates of local recurrence and micro-metastases even for those considered surgically curable malignant tumors, renders clinical management challenging. About $80 \%-$ $90 \%$ of malignancies are associated with cholelithiasis as a risk factor. ${ }^{14}$ Pure cholesterol stones greater than $1.5 \mathrm{~cm}$ are associated with adenosquamous and squamous cell carcinomas while increased size of the calculi may increase the risk of malignant transformation. ${ }^{14}$

Among the aggressive biliary tract malignancies, carcinoma of gallbladder is most common with the shortest median survival time mainly due to the lack of screening efforts. ${ }^{15}$ Pancreatic duct disruptions due to trauma or pancreatitis followed by release of pancreatic secretions seems to play an important role in the formation of pseudopancreatic cyst. ${ }^{16}$ This cyst is mostly associated with acute pancreatitis. In the paediatric population, an association of this cyst was found with trauma, viral illness, biliary tract disease, states of intracranial hypertension and also with steroids. Trauma is the most common cause of pancreatic pseudocysts in children. ${ }^{17}$

Acute pancreatitis leads to necrosis of peri-pancreatic tissue or parenchyma which can cause liquefaction and subsequent organization resulting in pseudocysts. ${ }^{18}$ Chronic pancreatitis leads to an acute exacerbation of pancreatitis or progressive ductal obstruction which can also lead to pseudocyst formation. ${ }^{18}$ There is no specific treatment for most of the pancreatic pseudocysts because it resolves spontaneously. However, drainage may be required when symptoms due to compression of adjacent organs appear or when complications like rupture, infection or bleeding arise. ${ }^{19}$ Gallbladder carcinoma is associated with many diseases but association of pseudopancreatic cyst with gallbladder carcinoma and gallstones has never been investigated.

\section{Conclusion}

Carcinoma of gallbladder with pseudo-pancreatic cyst is an unusual presentation. The possibility of both pathologies in the same case is considered to be a rare and novel occurrence.

\section{References}

1. Lazcano-Ponce EC, Miquel JF, Muñoz N, Herrero R, Ferrecio C, Wistuba II et al. Epidemiology and molecular pathology of gallbladder cancer. CA: a cancer journal for clinicians. 2001; 51(6): 349-64. Doi: 10.3322/canjclin.51.6.349

2. Shaffer EA. Gallbladder cancer: the basics. Gastroenterol Hepatol (NY). 2008; 4(10): 737-41. PMID: 21960896

3. Randi G, Franceschi S, La Vecchia C. Gallbladder cancer worldwide: geographical distribution and risk factors. IJC. 2006; 118(7): 1591-602. Doi: 10.1002/ijc.21683

4. Duffy A, Capanu M, Abou-Alfa GK, Huitzil D, Jarnagin W, Fong $Y$ et al. Gallbladder cancer (GBC): 10-year experience at memorial Sloan-Kettering cancer centre (MSKCC). J. Surg. Oncol. 2008; 98(7): 485-9. Doi: 10.14740/wjon951w

5. Lewis JT, Talwalkar JA, Rosen CB, Smyrk TC, Abraham SC. Prevalence and risk factors for gallbladder neoplasia in patients with primary sclerosing cholangitis: evidence for a metaplasiadysplasia-carcinoma sequence. Am J Surg Pathol. 2007; 31(6): 907-13. Doi: 10.1097/01.pas.0000213435.99492.8a

6. Zatonski WA, Przewozniak K, Lowenfels AB, Boyle P, Maisonneuve $\mathrm{P}$, Bueno de Mesquita $\mathrm{HB}$ et al. Epidemiologic aspects of gallbladder cancer: a casecontrol study of the SEARCH Program of the $\mathrm{JNCl}$. 1997; 89(15): 1132-8. Doi: 10.1093/jnci/89.15.1132

7. Rashid A, Ueki T, Gao YT, Houlihan PS, Wallace C, Wang BS et al. K-ras mutation, p53 overexpression, and microsatellite instability in biliary tract cancers: a population-based study in China. Clin Cancer Res. 2002; 8(10):3156-63. PMID: 12374683

8. Lai HC, Chang SN, Lin CC, Chen CC, Chou JW, Peng $\mathrm{CY}$, et al. Does diabetes mellitus with or without gallstones increase the risk of gallbladder cancer? Results from a population-based cohort study. J Gastroenterol. 2013;48(7):856-865. Doi: $10.1007 / s 00535-012-0683-z$ 
9. Dutta U, Nagi B, Garg PK, Sinha SK, Singh K, Tandon RK. Patients with gallstones develop gallbladder cancer at an earlier age. Eur J Cancer Prev. 2005; 14(4): 381-5. PMID: 16030429

10. Bahari HM, Abdullah I. Endoscopic transgastric drainage of pseudopancreatic cyst. Med J Malaysia. 1982;37(4):316-7. PMID: 7167081

11. Imrie CW, Buist LJ, Shearer MG: Importance of cause in the outcome of pancreatic pseudocysts. Am J Surg 1988; 156: 159-62. Doi: 10.1016/s00029610(88)80055-2

12. Barthet M, Bugallo M, Moreira LS, Bastid C, Sastre B, Sahel J: Man-agement of cysts and pseudocysts complicating chronic pancreatitis. A retrospective study of 143 patients. Gastroenterol Clin Biol.1993; 17: 270-6. PMID: 8339886

13. Ammann RW, Akovbiantz A, Largiader F, Schueler G: Course and outcome of chronic pancreatitis. Longitudinal study of a mixed medical surgical series of 245 patients. Gastroenterol. 1984; 86:820-8. PMID: 6706066
14. Hundal R., Shaffer E.A. Gallbladder cancer: epidemiology and outcome. Clin. Epidemiol. 2014; 6(5 Pt 1): 99-109. Doi: 10.2147/CLEP.S37357

15. Zhu AX, Hong TS, Hezel AF, Kooby DA. Current management of gallbladder carcinoma. Oncologist. 2010; 15(2): 168-181. doi:10.1634/theoncologist.2009-0302

16. Habashi S, Draganov PV. Pancreatic pseudocyst. WJG. 2009; 15(1): 38. Doi: 10.3748/wjg.15.38

17. Tomar S, Bakhshi S, Kabra SK, Arya LS. Pancreatic pseudocyst complicating treatment of acute lymphoblastic leukemia. Indian pediatric. 2003; 40(7): 670. Doi: 10.1007/s13193-013-0250-y

18. Udeshika WA, Herath HM, Dassanayake SU, Pahalagamage SP, Kulatunga A. A case report of giant pancreatic pseudocyst following acute pancreatitis: experience with endoscopic internal drainage. BMC research notes. 2018; 11(1): 262 . Doi: 10.1186/s13104-018-3375-9

19. Devangan M, Sonkar SK, Sharma S. A rare case of pancreatic pseudocyst involving liver and spleen. Int J Med Sci Res Pract. 2015; 2:150-2. 